\title{
La poética del cataclismo
}

\author{
Manuel Guillén
}

Cormac McCarthy, La carretera. Trad. de Luis Murillo Fort. Barcelona, Mondadori, 2007.

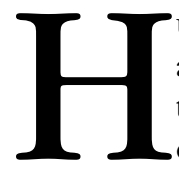

ubo un tiempo sin vida en este planeta. Hubo un tiempo sin seres animados y sin procesos vitales autónomos. Hubo también un tiempo sin seres humanos. Hasta donde sabemos, la emergencia de todo esto es más bien una especie de anomalía en el universo. Lo contrario es la constante. Una desértica inmensidad autorregulada en el espacio y el tiempo. ${ }^{1}$

Sin embargo, ha habido todo eso. La emergencia de la vida y los azares que la han llevado hasta la exitosa expansión de las criaturas con mayor inteligencia que ha conocido el planeta, y buena parte del cosmos escrutado, es un acontecimiento irreversible. Al surgir los seres humanos, tras un largo proceso de creación de sí mismos en lo que hemos dado en llamar "época prehistórica", surgió con ellos la progresión de su modo de ser, su historia y su destino.

Este modo peculiarísimo de afianzarse en la Tierra ha dado al hombre un cariz extraordinario; no sin razón se ha concebido la raza humana como el prodigio de la evolución. Pero la vasija de los prodigios ha sido también la de las abominaciones. Desde su expansión como especie dominante en el planeta, la humanidad reconoció la ambivalencia inherente a su andar por el mundo. Las grandezas civilizatorias han estado siempre acompañadas de los más diversos dislates plagados de locura y crueldad.

Desde esta visión de las cosas, puede concebirse también la contraparte del desarrollo último de la razón. Un cierre cataclísmico de su devenir. Una fase tenebrosa imbricada con la luminosidad de su evolución. No en vano desde tiempos antiguos se ha pensado en la posibilidad del cierre estrepitoso del ciclo humano en la Tierra.

${ }^{1}$ Para un panorama general sobre la emergencia de la vida en la Tierra y sus avatares en el tiempo de inmenso aliento, véase Carl Sagan, The Varieties of Scientific Explanation. Nueva York, The Penguin, 2006, especialmente el capítulo 3: "The Organic Life". 
La concepción apocalíptica plantea un cierre catastrófico de la era histórica. Sin duda piensa en el fin de ésta, y tal es su sentido recalcitrante: "El apocalipsis es de carácter escatológico (en este caso, la raíz es eschatos, lo más lejano o lo máximo): trata del fin de la época presente y de la edad que vendrá"; 2 pero ante todo trata de un tiempo más allá del tiempo efectivo, de un ultra tiempo en el que la destrucción de la temporalidad histórica real es la condición de la revelación, sea ésta del tipo que fuere:

Apocalipsis no es sólo un sinónimo de desastre, cataclismo o caos. En realidad, es sinónimo de "revelación", y si la revelación judeocristiana del fin de la historia incluye - de hecho, cataloga- desastres, también describe un orden milenario que representa la antítesis potencial de los innegables abusos de la historia humana. Aunque es verdad que un agudo sentido de perturbación y de desequilibrio temporal es la fuente del pensamiento y el relato apocalíptico, y es siempre integral a éste, también lo es la convicción de que la crisis histórica tendrá el efecto purificador de una renovación radical. ${ }^{3}$

Más allá de los sucesos de la historia se encuentra un destino diverso. El apocaliptismo tradicional es, en última instancia, redentor. Plantea la necesidad de la desaparición de lo existente por medio de los más variados terrores, pero con la finalidad de que la destrucción dé luz a un mundo nuevo. Un ultra mundo en el que aquello que no fue posible dentro de la historia, sea finalmente conseguido: la armonía, la justicia, el orden divino de las cosas.

El sentido del apocalipsis, de esta guisa, fue metamorfoseado en la modernidad. Perdió buena parte de su carácter teológico, pero no su significado de finalidad catastrófica como opuesta a lo que en la historia ocurre, si bien las esperanzas de un mundo mejor quedaron o bien tenuemente afirmadas o definitivamente olvidadas para una mejor ocasión.

El ciclo de vida del apocaliptismo moderno ha llegado con contundencia hasta nuestros días. En la deflación contemporánea de los grandes presupuestos de la modernidad - el sujeto libre y cognoscente, el Estado nacional y la cultura humanística-, hemos presenciado una renovada urgencia apocalíptica, que a decir de Fredric Jameson ha tenido su más destacado representante en las figuraciones umbrosas del cyberpunk. ${ }^{4} \mathrm{El}$ cyberpunk plantea un porvenir atroz cuya materialización cuenta con todas las probabilidades a favor. Es el paso siguiente en la desaforada lógica del desarrollo de nuestra civilización.

\footnotetext{
${ }^{2}$ Lois Parkinson Zamora, Narrar el apocalipsis. México, FCE, 1994, p. 22.

${ }^{3}$ Ibid., pp. 21-22.

${ }^{4}$ Véase Fredric Jameson, Las semillas del tiempo. Madrid, Trotta, 2000.
} 
De esta manera, la estética cyberpunk recoge y proyecta en un cúmulo de obras, una abigarrada imaginería crepuscular en la que se mezclan los más inquietantes avances de la cibernética, la ingeniería genética y la física nuclear, con el montaraz resurgimiento de atavismos tribales, místicos y oscurantistas -la neobarbarie- de la así llamada época postindustrial.

El cyberpunk, en fin, presenta un mundo al borde del caos, la desesperanza y la anomia. La ebullición de paranoia, pérdida de sentido y desintegración social que el género machaca en sus más acabados momentos, lo ha consolidado como la tierra más fértil para la condena de nuestros tiempos, cuya acelerada decadencia no parece dirigirse a una edad diversa de la que la sombría perspectiva del hijo rebelde de la ciencia-ficción clásica hace patente.

A través del invariable punto de partida de la desintegración o decadencia del mundo tal y como lo conocemos, ya bien por la destrucción voluntariosa por medios tecnológicamente catastróficos, como la guerra nuclear, las invasiones o los riesgos tecnobiológicos desatados; ya por la cortocircuitación del sistema debido al peso de sus propias aporías políticas y sociales, ya por la aleatoriedad del comportamiento del organismo terrestre con su estela de disrupciones meteorológicas a gran escala, la acometida de plagas inesperadas o el avance inexorable de nuestros enemigos microscópicos, el cyberpunk retrotrae a la civilización a un punto de no retorno.

En la era posmoderna, entonces, el gran género apocalíptico subrayado por Jameson marca la ruta de la crítica radical del modo de ser de la civilización contemporánea, sin atisbos de mejoría o renacimiento virtuoso de los saldos que de ella quedarán tras el omega de su devenir; esto es así, puesto que depende de un cambio fundamental en la manera de concebir el cerrojazo del periplo humano terrenal: éste se encuentra ya, de manera exclusiva, en manos del propio hombre.

La posibilidad del fin de los tiempos siempre fue un privilegio divino hasta la llegada de la modernidad avanzada. Después del dominio de la fisión nuclear con fines bélicos, el destino de la humanidad estuvo realmente en sus propias manos. El mapa de los desastres que las tradiciones míticas y literarias habían planteado como un atisbo del destino posible de los seres humanos, fue reconfigurado en clave realista, en el aquí y el ahora de la posibilidad del extermino total del hombre y de buena parte de la vida del planeta. La humanidad ha incubado su propio destino catastrófico y el haber tomado semejante elección opera de manera inquietante en la conciencia profunda de la mayoría de los habitantes del planeta: la constatación de ser la única especie capaz de dar cuenta de sí misma.

Todo ello se hace presente en la última novela de Cormac McCarthy, renovada y descarnada recreación del cyberpunk de principios de los ochentas. El pasaje de cierre de La carretera, a manera de síntesis literaria, anuda los cabos 
de todo lo antedicho, enfatizando el destino trágico de una especie condenada a desaparecer, al tiempo que evoca la nostalgia por la inexistencia de aquello que fuera necesario e inigualable: el hombre. Si bien fija plenamente el espacio de posibilidad terrenal de la vida humana que fue y ya no es, el milenario contenedor medioambiental cuya existencia nos rebasa y nos desborda, al hacerlo, consigna el espacio en blanco, el vacío, el hueco del mundo que ha dejado la inminente desintegración del ser humano:

Una vez hubo truchas en los arroyos de la montaña. Podías verlas en la corriente ambarina allí donde los bordes blancos de sus aletas se agitaban suavemente en el agua. Olían a musgo en las manos. Se retorcían, bruñidas y musculosas. En sus lomos había dibujos vermiformes que eran mapas del mundo en su devenir. Mapas y laberintos. De una cosa que no tenía vuelta atrás. Ni posibilidad de arreglo. En las profundas cañadas donde vivían todo era más viejo que el hombre y murmuraba misterio (p. 210).

Olvidado por el planeta, que sin él habrá de seguir su dinámica cósmica imparable (aunque ciertamente no sin heridas infligidas por el poder humano mega destructivo), más añeja y perenne que la razón humana, la abrupta disolución de lo antrópico no puede sino ser pensada de manera funesta: fue el resultado de una cadena de elecciones predeterminadas por un destino irrefrenable. Destino que "no tenía vuelta atrás", "ni posibilidad de arreglo", trágico al fin.

La tragedia civilizatoria contemporánea está aunada al advenimiento de la era tecnocientífica, que trastrocó las fantasías del fin del mundo que plagaron la imaginería occidental durante centurias, volviéndolas realidades ominosas. Lo que fueron visiones desenfrenadas de iluminados o locos religiosos, de poetas y creadores con alta sensibilidad para la simbología catastrófica, palidecen ahora ante la precisa descripción de lo que, de hecho, ocurrirá el día en que el "arma absoluta" 5 sea desatada por decenas a lo largo y ancho del planeta.

En este estado de cosas se inscribe la fábula novelística de McCarthy, quien retoma un tema prácticamente olvidado por una generación entera desde que hace veinte años terminara la Guerra fría, junto con la fantasía del comunismo en un solo país y el malogrado intento soviético de mantener una fuerza subimperial en su zona geográfica de influencia.

Sin embargo, más allá de la pragmática bélico-política internacional de nuestra era, prevalece la urgencia vital, tecnológica y moral sobre la era

${ }^{5}$ El término lo usa André Glucksmann, Dostoievski en Manhattan. Madrid, Taurus, 2002, p. 16. 
atómica. Porque el olvido generacional de la imaginería global relativa al "invierno nuclear"6 no significa que su funesta presencia haya desaparecido o haya sido superada. La existencia de millares de cabezas nucleares plenamente funcionales a lo largo y ancho del planeta, sigue siendo una realidad execrable que implica con necesidad la posibilidad de la extinción del sistema social, e incluso de la especie humana misma, tal y como los hemos conocido hasta nuestros días.

Si en los tiempos de la Guerra fría esto era cierto, lo sigue siendo sin ápice de mejora el día de hoy. En este orden de ideas, la novela de McCarthy tiene un claro sesgo moral que confronta al estado de cosas que ha hecho posible una realidad de este tipo, inscribiéndose así en la larga tradición de apocaliptistas literarios de la modernidad: "Los novelistas que emplean elementos apocalípticos, tal como los apocaliptistas bíblicos, a menudo critican las actuales prácticas políticas, sociales y espirituales, y proponen los medios de oponérseles y de superarlas. Crean ficciones globales de orden histórico, dramas universales que asignan valor moral a los acontecimientos aislados y a la conducta individual". ${ }^{7}$

Debido a su inquietante impronta nihilista, el sesgo moral de la obra nunca llega a ser moralizante, sino crítico y terrorífico. Convertido en un apocaliptista posmoderno, McCarthy rebasa el pastiche y fundamenta su narración en el suelo viscoso de una sociedad que ha llegado al paroxismo y a la parodia de sí misma. En el camino, se ha convertido en una civilización del despilfarro, el pseudohedonismo rampante y la pérdida de toda cordura en las interacciones cotidianas. En ella, las fuerzas de la neobarbarie y el desenfreno individualista han ganado la batalla a los esfuerzos librescos, institucionales, filosóficos, del humanismo de viejo cuño. ${ }^{8}$

Carente de amarras morales trascendentes y habiendo traicionado sus mejores ideales trascendentales, la civilización hipermoderna comenzó su sendero de no retorno el 16 de julio de 1945; con el Proyecto Manhattan, el destino de la modernidad salvaje quedó marcado para siempre. Razón por la que el

6 "Invierno nuclear" es un término que refiere al desastre medioambiental que algunos científicos creen que ocurriría tras una guerra nuclear a gran escala. De acuerdo con esta teoría, los efectos acumulativos del calor, la explosión, la radiación y el polvo lanzados al aire en un intercambio bélico así, destruirían la capa de ozono y bloquearían la luz solar necesaria para calentar la Tierra. El efecto sería global y tal vez tendría como resultado la extinción de la mayoría de las formas de vida en la Tierra”. Véase Eric A. Croddy y James J. Wirtz, eds., Weapons of Mass Destruction. Santa Bárbara, ABC-CLIO, 2005, vol. 2: Nuclear Weapons, p. 267.

${ }^{7}$ Véase L. Parkinson Zamora, op. cit., p. 14.

${ }^{8} \mathrm{Al}$ respecto, véase Peter Sloterdijk, Normas para el parque humano. Madrid, Siruela, 2006. 
también autor de Blood meridian eligió el tema de la guerra de destrucción total como antecedente velado de los sucesos narrados en La carretera.

De manera cierta, la conflagración del fin del mundo no es el tema central de la obra, sino las consecuencias de la misma, el mundo del hombre a punto de apagarse para siempre. No obstante, el autor da breves pero contundentes indicios de que tal fue la causa de la resolución última de la trayectoria humana por el planeta: "Por la tarde la forma lóbrega de otra ciudad costera, el grupo de altos edificios ligeramente torcido. Pensó que los armazones de hierro se habían ablandado con el calor y que al contraerse después no habían dejado los edificios a plomo" (p. 200). Sólo una estela de calor radioactivo en forma de ola térmica sería capaz de reblandecer en grupo los rascacielos playeros de lo que muy bien pudo haber sido la ciudad de Miami, Florida.

McCarthy teje fino y en ningún momento hace explícito el sitio geográfico en el que se desarrolla el andar atormentado de un padre y su hijo por una "tierra cauterizada" (p. 146), aunque muy bien podría pensarse que es el lugar de lo que actualmente es el territorio de Estados Unidos de América. No hace explícita la geografía, porque los mapas ya no nombran nada después del cataclismo atómico y porque está más preocupado por hacer ver las aporías y dislates de un tiempo civilizatorio que, debido a sus propias cualidades estructurales, no tuvo más remedio que implotar, autodestruyéndose.

La trayectoria de dicho tiempo estructural, que es el de la modernidad-posmodernidad, coincide con lo que desde el siglo XIX se ha afirmado como un augurio perturbador de las consecuencias de dicho periodo sociohistórico: el nihilismo. Desde este punto de vista, puede observarse una estructura de sentido particular que ha dado como resultado la paradójica bivalencia entre un conocimiento y una tecnología sin igual y una erosión creciente de la mayoría de los valores que forjaron la civilización moderna. El sentido del nihilismo en su máxima expresión. O, en la versión del nihilismo del novelista estadounidense: "Tiempo prestado y mundo prestado y ojos prestados con que llorarlo" (p. 100).

Por todo esto, tras la destrucción de todo lo existente y con la raza humana vuelta hilachos de lo que fue y a punto de extinguirse para siempre, en la novela del escritor estadounidense accedemos a dos terribles realidades que se niegan a morir: la inoculación mercantilista del mundo de la vida y la sed de aniquilación del hombre por el hombre, aun después de una catástrofe voluntariosa de orden universal.

La primera resalta su contundencia por el vacío que dejó, por la rutilancia que su penetrabilidad extrema marca en la negación de su existencia; su inexistencia es prácticamente equivalente a la inexistencia del propio ser humano.

A las afueras de la ciudad llegaron a un supermercado. Varios coches viejos en un aparcamiento sembrado de desperdicios. Dejaron allí el 
carrito y recorrieron los sucios pasillos. En la sección de alimentación encontraron en el fondo de los cajones unas cuantas judías verdes y lo que parecían haber sido albaricoques, convertidos desde hacía tiempo en arrugadas efigies de sí mismos [...] Junto a la puerta había dos máquinas de refrescos que alguien había volcado y abierto con una palanca. Monedas esparcidas por la ceniza del suelo. Se sentó y paseó la mano por las tripas de las máquinas y en la segunda palpó un cilindro frío de metal. Retiró lentamente la mano y vio que era una Coca-Cola (pp. 22-23).

Imbricados con el universo de mercancías que el sistema de producción del capitalismo en su fase última creó de manera incesante, los seres humanos han quedado fundidos con esa férrea malla exoorgánica que es la esfera vital productivo-mercantilista de nuestro horizonte de subsistencia; y tal parece que separados de ella somos unos parias errabundos en un mundo sin sentido. Una especie de seres "esqueléticos e inmundos como adictos callejeros" (p. 132).

Encontrar una imposible lata de Coca-Cola y beberla como el último elixir de un mundo en estado de putrefacción, pone de relieve el absurdo drama que se ha venido protagonizando en los últimos quinientos años (aunque sin duda de manera furiosa en los últimos cien). La esencia del significado del mundo es la esencia misma de su modo de producción. Atroz como lo es, sin éste sólo queda un vasto planeta, "quemado hasta donde alcanza la vista, renegridas formas rocosas despuntando entre los bancos de ceniza y oleadas de ceniza elevándose para alejarse sobre la tierra baldía. La senda de un sol opaco moviéndose invisible más allá de las tinieblas" (p. 17).

La segunda realidad aborrecible expande su virulencia en un mundo postapocalíptico a la manera de la literal devoración entre los hombres. Si en el sistema social inmediato anterior al cataclismo nuclear -el capitalismo financiero globalizado-, el canibalismo era una realidad metafórica (aunque no por ello menos salvaje) en los niveles económico, político y societal, en el mundo del invierno nuclear dicha práctica tabú emerge con la bestialidad añadida de todo lo aprendido en el sistema-mundo que posibilitó la hecatombe nuclear.

Cuando el par de caminantes del relato encuentran una casa en ruinas y se disponen a escrutarla, se dan cuenta de que alguien habita en ella. Muy pronto descubrirán que en el sótano de la misma, la gente que la ha tomado en posesión guarda ganado humano para su consumo. Hordas de esta clase se encuentran aquí y allá en los restos del mundo que queda. Pero antes de hacer este descubrimiento terrible, el panorama de los alrededores ya lo anuncia:

En el jardín había una vieja grada de hierro apoyada en unos pilares de ladrillos superpuestos y alguien había metido entre sus dientes un caldero de hierro colado de ciento cincuenta litros como los que se 
usaban antes para fundir grasa de cerdo. Debajo había cenizas de un fuego y leños renegridos. Más allá un pequeño carro con neumáticos. Todas estas cosas las vio y no las vio. Al fondo del patio había un ahumadero de madera y un cobertizo (p. 84).

Algo que los seres humanos desde tiempos inmemoriales han aprendido hasta el tuétano, al punto de interiorizar sin más como parte de su naturaleza, es el usufructo para beneficio propio de prácticamente todas las especies del planeta. En un entorno en el que todo el ganado tradicional ha sido exterminado, las habilidades adquiridas permanecen. El único ganado a disposición -y éste también escasea- es de carácter antrópico. La referencia al caldero para derretir grasa de cerdo en los tiempos previos a la gran conflagración, manifiesta el espantoso designio de los últimos seres humanos: al fin pueden verse como vieron a tantos de los grandes mamíferos en la era de la abundancia: como un producto alimenticio listo para ser consumido.

Porque en el estado poscataclísmico así planteado, el ser humano se halla ya en retirada; ha conseguido, finalmente, comenzar su involución, llevar al último término la meta del nihilismo; la negación de su ser. En este entorno anómalo, se materializan de manera violenta y descarnada las advertencias que ya Nietzsche anunciara en su momento. Con el canibalismo sistemático en un mundo desolado, el antiguo augurio del pensador alemán se vuelve realidad opresiva, obscena, voraz: "junto con el miedo hacia el hombre hemos sacrificado también el amor hacia él, el respeto hacia él, la esperanza en él, y aun la voluntad de él. En adelante, la visión del hombre cansará [...], ¿qué es hoy el nihilismo sino esto? [...] Estamos cansados del hombre".

El nihilismo en su fase radical, sangrienta, maloliente, implica la destrucción de la raza humana por parte de sus propios miembros; ya no en el nivel masivo, como ocurriera con la guerra atómica, que fue, sino en la intimidad de la brutalidad, en la disposición de los pocos cuerpos que quedan como alimento, en la erección de nuevas formas de ganado, en la búsqueda de un nuevo stock alimenticio que, además, es el pretexto idóneo para dar rienda suelta a la connatural crueldad de la especie humana.

En un acto de verdadera retrotracción de todo cuanto de valioso pudo haber en el hombre, a diferencia de la voluntad de sobreponerse a un entorno que lo mantenía a raya, como en los tiempos arcaicos, en lo que Peter Sloterdijk ha llamado la "paleopolítica", la cual es "el milagro de la repetición del hombre por el hombre. Se ejerce y se logra en un medio que, en alguna medida, parece querer dificultar a los hombres el arte de reponerse en los hijos" ${ }^{10}$

${ }^{9}$ Cf. Friedrich Nietzsche, La genealogía de la moral. Madrid, Tecnos, 2007, p. 84.

${ }^{10} C f$. P. Sloterdijk, En el mismo barco. Madrid, Siruela, 2008, p. 24. 
la rebaba humana que ha quedado tras la guerra nuclear no hace sino el esfuerzo de acabar con esos hijos, de jalonar al exterminio definitivo de la especie, de aniquilar para siempre su andar por el planeta:

Estaba examinando el perímetro del claro cuando el chico se dio la vuelta y sepultó la cara en su cuerpo. El hombre giró rápidamente para ver qué había pasado. ¿Qué?, dijo. ¿Qué pasa? El chico meneó la cabeza. Oh, papá, dijo. Se volvió para mirar otra vez. Lo que el chico había visto era un bebé carbonizado ennegreciéndose en el espetón, sin cabeza y destripado. Cogió al chico en brazos y regresó a la carretera estrechándolo con fuerza. Lo siento, susurró. Lo siento (pp. 147-148).

La humanidad lo logró al fin. Como predijeron los adivinos místicos exaltados en sus abigarradas visiones del fin de los tiempos, y como con mucha mayor sobriedad analítica observara Nietzsche al detectar los endebles fundamentos éticos y culturales de la modernidad desbocada hacia el futuro, finalmente el esfuerzo racionalizador del iluminismo, destacado de manera penetrante por Adorno y Horkheimer, ${ }^{11}$ deshizo el mundo.

Una inescrutable lógica del poder hizo explotar todas las bombas, mancillando al planeta y despedazando la vida del hombre, marcando el umbral de su último aliento cósmico. Tal era el destino de la raza humana. Tal su designio voluntarioso, imposible de contener. En la retrospectiva postapocalíptica del mundo en hebras, puede comprenderse sin mácula el sentido de la totalidad del tiempo histórico; del ser humano y sus obras. No era otro, nunca lo fue, más que la aniquilación de todo lo construido, la resquebrajadura terminal de los siglos de conocimiento acumulado; el uso de dicho conocimiento para retrotraernos al año cero. Antes, incluso, al tiempo sin humanos.

Al hacerlo, y a pesar del ultraje recibido por los artefactos de guerra del hombre, el planeta fue liberado. Ése es el resquicio esperanzador del apocaliptismo posmoderno de McCarthy. Sin los seres más paradójicos que ha visto caminar sobre ella, la Tierra se libera de sus amarras, calla las voces extrañas de unos extravagantes primates y vuelve a su sonido cadencioso y al silencio, flotando impasible en la inmensidad del cosmos: "El frío y el silencio. Las cenizas del mundo difunto trajinadas de acá para allá por los crudos y transitorios vientos en el vacío. Llevadas, esparcidas y llevadas de nuevo. Todo desencajado de su apuntalamiento. Sin soporte en el viento cinéreo" (pp. 14-15).

${ }^{11} \mathrm{Cf}$. Theodor Adorno y Max Horkheimer, Dialéctica del iluminismo. Buenos Aires, Sudamericana, 1987. 